\title{
田
}

\section{O ENLACE ENTRE EDUCAÇÃO E DESENVOLVIMENTO REGIONAL NO PROCESSO DE INTERIORIZAÇÃO DA UNIVERSIDADE FEDERAL DE PERNAMBUCO}

The link between education and regional development in the interiorization process of the

Federal University of Pernambuco

\author{
Tatianne Amanda Bezerra da Silva* \\ Jamerson Antonio de Almeida da Silva** \\ (c) (1)(2)
}

\section{RESUMO}

O presente artigo se situa no campo de pesquisa acerca da Política Educacional e, mais especificamente, no âmbito dos estudos sobre as Políticas de Ensino Superior brasileiras. Dentro desse campo de estudos, nos propomos a examinar as intencionalidades presentes no processo de interiorização das universidades brasileiras desenvolvido no governo Lula da Silva (2003-2006 e 2007-2010), tendo como base a experiência da Universidade Federal de Pernambuco (UFPE). No movimento de criação do objeto de pesquisa, utilizamos o referencial epistemológico marxista, que aponta para a necessidade de situarmos o fenômeno no caráter histórico que define o modo de produção capitalista. Como caminho metodológico adotado, utilizamos abordagem qualitativa, revisão de literatura e análise de documentos e publicações sobre o assunto. No que se refere à análise de dados, fizemos uso do caminho metodológico da hermenêutica dialética.

\section{PALAVRAS-CHAVE}

Interiorização. Governo Lula. Universidade Federal de Pernambuco.

\section{ABSTRACT}

The present article is located in the field of research on Educational Policy and, more specifically, in the scope of studies on the Policies of Higher Education in Brazil. Within this field of study, we propose to examine the intentionalities present in the

\footnotetext{
* Assistente social. Mestra em Educação Contemporânea (UFPE). Doutoranda em Educação pela Universidade Federal de Pernambuco. (UFPE, Recife, Brasil). Av. Prof. Moraes Rego, 1235, Cidade Universitária, Recife (PE), CEP.: 50670-901. E-mail: <tatiannebezerra1@hotmail.com>. ORC ID: <https://orcid.org/0000-0002-4296-1219>.

** Doutor em Educação. Professor Adjunto IV do Curso de Pedagogia da Universidade Federal de Pernambuco. (UFPE, Recife, Brasil). Av. Prof. Moraes Rego, 1235 - Cidade Universitária, Recife (PE) CEP.: 50670-901. E-mail: <jamersonufpe@gmail.com>. ORC ID: <https://orcid.org/o000-0002-4198-8049>.
} 
internationalization process of the Brazilian universities developed in the Lula da Silva government (2003-2006 and 2007-2010), based on the experience of the Universidade Federal de Pernambuco (UFPE). In the creation movement of the research object, we use the Marxist epistemological framework, which points to the need to situate the phenomenon in the historical character that defines the capitalist mode of production. As a methodological approach adopted, we used a qualitative approach, literature review and analysis of documents and publications on the subject. As far as data analysis is concerned, we have used the methodological path of dialectical hermeneutics.

KEYWORDS: Interiorization. Government Lula. Federal University of Pernambuco.

Submetido em: 10/2/2018.

Revisado em: 4/5/2018.

Aceito em: 21/5/2018.

\section{INTRODUÇÃO}

Decorrido quinze anos desde a primeira fase de expansão e a interiorização dos campi das Universidades Federais brasileiras promovidas pelo governo Lula da Silva (2003-2006 e 2007-2010), as problematizações críticas acerca do fenômeno ainda permanecem vivas. Junto à sua importância para população, a ampliação das vagas na rede federal de ensino brasileira veio acompanhada de empecilhos e desafios que precisam ser mais bem apreendidos.

É no contexto de compreensão desses múltiplos entraves que situamos nosso estudo, nos propondo a examinar as intencionalidades presentes no processo de interiorização das universidades brasileiras desenvolvido no governo Lula da Silva, tendo como base a experiência da Universidade Federal de Pernambuco (UFPE).

No movimento de criação do objeto de estudo, utilizamos o referencial epistemológico marxista, que aponta para a necessidade de situarmos o fenômeno no caráter histórico que define o modo de produção capitalista. Como caminho metodológico adotado, utilizamos abordagem qualitativa, revisão de literatura e análise de documentos sobre o assunto.

No trato dos documentos, o Projeto de Interiorização da Universidade Federal de Pernambuco (UNIVERSIDADE FEDERAL DE PERNAMBUCO, 2005a) foi considerado dado central de nosso trabalho. Nele estão contempladas as bases gerais do processo de interiorização desenvolvido pela UFPE. Assim sendo, o documento é capaz de nos fornecer os subsídios necessários para pensarmos as intencionalidades presentes no processo de interiorização da referida universidade.

No que se refere à análise de dados, fizemos uso do caminho metodológico da hermenêutica dialética. A sua grande contribuição se dá na medida em que, segundo Minayo (2014), considera como alicerce da comunicação as relações historicamente dinâmicas, contraditórias e antagônicas entre classes, grupos e culturas. Ou seja, entende a complexidade das comunicações que, embora possam parecer iguais para todos, escondem e expressam a realidade conflitiva das desigualdades, da dominação, da exploração e também da resistência e conformidade. Para a autora: 


\begin{abstract}
Uma análise compreensiva ancorada na hermenêutica-dialética busca apreender a prática social empírica dos indivíduos em sociedade em seu movimento contraditório. Portanto, tendo em conta que os indivíduos vivendo em determinada realidade pertencem a grupos, classes e segmentos diferentes, são condicionados por tal momento histórico e por isso, podem ter simultaneamente interesses coletivos que os unem e interesses específicos que os distinguem e os contrapõem. Sendo assim, a orientação dialética de qualquer análise diz que é fundamental realizar a crítica das ideias expostas nos produtos sociais (textos, monumentos, instituições) buscando, na sua especificidade histórica, a cumplicidade com seu tempo; e nas diferenciações internas, sua contribuição à vida, ao conhecimento e às transformações (MINAYO, 2014, p. 347).
\end{abstract}

Do ponto de vista de Minayo (2014), a hermenêutica dialética considera que nada se constrói fora da história e qualquer comunicação necessita ser situada no contexto no qual foi produzida, haja vista que expressa a totalidade dinâmica das relações de produção e reprodução na qual se insere. Ademais, compreende os seres humanos não como meros objetos de investigação, mas também como sujeitos de suas relações. Para a autora, a proposta da hermenêutica-dialética é a que oferece um quadro referencial mais completo para a análise do material qualitativo, não obstante, a técnica não apresenta instrumentos pré-definidos para o processo de operacionalização analítica. Em vista disto, optamos por seguir passos próprios de operacionalização em nossa pesquisa, inspirados em indicações de Campos (2004) e Minayo (2014).

Para a escolha dos documentos do campo empírico, consideramos os critérios apresentados por Minayo (2014), são eles: exaustividade, representatividade, homogeneidade e pertinência. Foram realizadas leituras flutuantes do material, de modo a identificar quais documentos da UFPE davam os subsídios necessários para responder ao objetivo do estudo.

Considerados estes critérios, selecionamos os seguintes documentos: Anuário estatístico UFPE 2017: base 2016 (UNIVERSIDADE FEDERAL DE PERNAMBUCO, 2017), Projeto de interiorização da Universidade Federal de Pernambuco (UNIVERSIDADE FEDERAL DE PERNAMBUCO, 2005a) e Resolução n 03/2005, que cria o Centro acadêmico do Agreste e dá outras providências (UNIVERSIDADE FEDERAL DE PERNAMBUCO, 2005b). No trato dos documentos, conforme ressaltado, o Projeto de Interiorização da Universidade Federal de Pernambuco foi considerado dado central.

Em seguida à seleção documental, foi realizada a seleção da unidade de análise de nossa pesquisa. Determinou-se como unidade de análise temática expressa nos documentos. A unidade de análise foi definida a partir de uma categorização apriorística, ou seja, os pesquisadores estabeleceram, a partir de seu objetivo de estudo, uma categoria prédefinida. A partir deste elemento, definiu-se como unidade temática intencionalidades da interiorização da Universidade Federal de Pernambuco.

Uma vez definida a unidade analítica, realizou-se uma leitura exaustiva dos dados documentais, de modo a identificar os conteúdos semelhantes e classificá-los de acordo com a respectiva categoria. Terminado este esforço, realizamos a análise final, na qual os 
dados empíricos agrupados foram confrontados com os fundamentos teóricos e viceversa.

Considerando os elementos metodológicos acima elencados, nosso trabalho está organizado da seguinte forma: inicialmente examinamos como se configura as Políticas de Ensino Superior públicas brasileiras no contexto do social-liberalismo de Lula da Silva (2003-2006 e 2007-2010). Na sequência, expomos como se deu o processo de adesão da Universidade Federal de Pernambuco às políticas de expansão e interiorização do governo do Partido dos Trabalhadores (PT), bem como suas intencionalidades. Por fim, realizamos algumas considerações à guisa de conclusão.

\section{AS POLÍTICAS DE ENSINO SUPERIOR PÚBLICAS BRASILEIRAS NO GOVERNO LULA DA SILVA}

Antes de iniciarmos a discussão acerca das dimensões constitutivas das políticas de ensino superior no período Lula da Silva, torna-se necessário apresentar, ainda que brevemente, a base do planejamento assumida pelos governos do Partido dos Trabalhadores. Faz-se imprescindível expor os fundamentos que sustentaram as políticas sociais e econômicas empreendidas pela coalizão partidária liderada pelo PT, cuja marca é um novo movimento de intervenção estatal brasileiro no contexto do capitalismo mundial.

Como destaca Castelo (2012), temos, desde a segunda gestão de Fernando Henrique Cardoso (FHC) (1995-1998 e 1999-2002), uma crise conjuntural capitalista, que ameaça a hegemonia neoliberal em diversas regiões do planeta, o que leva as classes dominantes a iniciarem um processo de revisão dos principais pontos neoliberais. Surge, pois, uma revisão ideológica do neoliberalismo, isto é, "[...] uma tentativa político-ideológica das classes dominantes de dar respostas às múltiplas tensões derivadas do acirramento das expressões da 'questão social' e da luta política da classe trabalhadora" (CASTELO, 2012, p. 47). Trata-se, segundo o autor, da tentativa de acoplar uma agenda social ao projeto neoliberal, promovendo um sincretismo de medidas de estímulo a intervenções pontuais do Estado e do chamado Terceiro setor nas expressões mais explosivas da 'questão social', isso sem tocar evidentemente na estrutura do capitalismo.

O novo projeto, intitulado pelo autor como social-liberalismo, defende a possibilidade de conciliação de desenvolvimento econômico e social, isto é, da conciliação de interesses econômicos e sociais ou da criação de um clima de conciliação entre interesses de classes. "O social-liberalismo - internacional e brasileiro - busca promover um sincretismo entre o mercado e o Estado imaginariamente capaz de instaurar a justiça social" (CASTELO, 2012, p. 71). Nesse sentido, "[...] as desigualdades socioeconômicas deixaram de ser uma positividade em si [...] e passam a ser um dilema social a ser tratado pela burguesia e seus intelectuais" (CASTELO, 2012, p. 71).

Contudo, postula Castelo (2012), embora o social-liberalismo tenha chegado ao Brasil ainda durante o governo FHC, não se pode desconsiderar a força legitimadora que Lula e suas lideranças do PT injetaram no neoliberalismo latino-americano com sua adesão à ideologia social-liberal. Foi essa adaptação na direção econômica e social, sem 
interferência na estrutura e pautada na governabilidade, que permitiu certa aceitação da candidatura e eleição de Lula por parte dos setores da alta burguesia. Isto é, ele não se apresentava como ameaça ao sistema e, ao mesmo tempo, possibilitava a construção de um terreno social mais ameno diante das catástrofes neoliberais.

Esta suposta virada para esquerda não é exclusiva do Brasil, diversos países da América do Sul também a realizaram. Em quase todos os países da região foram eleitos, neste período, governos de orientação nacionalista, desenvolvimentista ou socialista, segundo Fiori (2013). Corroborando o autor, Freitas e Silva (2016) destacam como o movimento de discussão do novo modelo de desenvolvimento no contexto do social-liberalismo vem como uma alternativa de terceira via não somente para o Brasil, mas para outros países latino-americanos, como Chile e Argentina, que exercem um governo almejando um equilíbrio entre política social e econômica, com vistas ao chamado desenvolvimento com justiça social.

Trata-se de um modelo de desenvolvimento que, do ponto de vista econômico configurase como uma variante do neoliberalismo com maiores intervenções estatais e objetivando o crescimento econômico. É, nos termos de Almeida e Furtado (2017), uma versão do desenvolvimentismo em geral, mas não uma real alternativa ao neoliberalismo e sim um viés de resposta social-liberal à crise do capital. Assim, conclui-se que

A chegada do PT ao governo não teve um sentido contra-hegemônico. Ao
contrário, houve um processo de reforço da hegemonia política burguesa [...] no
Brasil, que se constituiu, por um lado, através de uma pequena melhora da
capacidade de consumo dos mais pobres (mesmo sem uma diminuição real da
desigualdade social), fruto da somatória de micropolíticas econômicas e políticas
sociais compensatórias favorecidas por um momento de melhora da situação
mundial. Por outro lado, houve o transformismo do PT e aliados, que passam a
defender a ordem social e fazer a contenção dos movimentos sociais. Em
terceiro lugar, o discurso do novo governo e de suas principais lideranças,
inclusive Lula da Silva, foi de rebaixamento das utopias e expectativas de
mudanças mais profundas, valorizando o melhorismo (sic) material imediatista e
rebaixado. Esse combinado permitiu que Lula-Dilma (PT) tirassem direitos,
dentro da democracia liberal, mantendo um apoio popular até 2012. Mas houve
também um reforço do aparato jurídico-coercitivo (ALMEIDA; FURTADO, 2017, p.
10).

Nesse sentido, a última década caracteriza-se por um novo projeto de desenvolvimento para o Brasil, que aponta para a retomada das intervenções estatais em políticas sociais e econômicas, destacando seu papel como indutor de crescimento nacional. Assim, na medida em que, no novo desenvolvimentismo, o aumento das intervenções públicas nas políticas sociais é considerado importante ferramenta de crescimento econômico, "[...] discutir as bases de um novo modelo de desenvolvimento decorre da importância em não separar a análise de políticas públicas e políticas econômicas" (FREITAS; SILVA, 2016, p. 79).

Na base desse novo padrão de desenvolvimento do Estado brasileiro, o Programa de Aceleração do Crescimento (PAC), anunciado em 2007, durante o governo Lula, mas que tem continuidade na gestão Dilma, anuncia, em grande parte, os eixos norteadores da perspectiva novo-desenvolvimentista. Nos termos de Jardim e Silva (2015), o PAC trata-se

Temporalis, Brasília (DF), ano 18, n. 35, jan./jun. 2018. 
da utilização “[...] de parcerias público-privadas visando à retomada do planejamento e à execução de grandes obras de infraestrutura social, urbana, logística e energética do país, com o intuito, segundo o governo, de contribuir para o desenvolvimento acelerado e sustentável da economia" (JARDIM; SILVA, 2015, p. 21).

Esse ponto de vista deixa marcas também na educação. Dentro da lógica novodesenvolvimentista, e em concordância com a perspectiva do Banco Mundial (BM), defende-se o papel fundamental exercido pela educação como propulsora do desenvolvimento e como estratégia para redução da pobreza e desigualdade social nos países periféricos. Seu marco estruturante nas políticas educacionais se desenhou no Plano de Desenvolvimento da Educação (PDE) (Decreto n. 6.094, de 24 de abril de 2007, que dispõe sobre a implementação do Plano de Metas Compromisso Todos pela Educação). Como esclarece Freitas e Silva (2016):

[...] os programas e ações que estruturaram o PDE, bem como seus pilares, buscaram aclarar a lógica de fazer política pública do governo de Lula da Silva no campo da educação, proclamando uma visão integrada e de longo prazo, com foco no desenvolvimento, inclusive com um conjunto de ações complexas para fomentar ciência e tecnologia com vistas ao aumento da competitividade internacional e ao crescimento virtuoso da economia no médio e no longo prazo (FREITAS; SILVA, 2016, p. 81).

Segundo as autoras, o PDE, tratado em âmbito federal como PAC da Educação, pela característica de um plano executivo, foi desenhado com forte apelo estratégico. Suas ações desenvolvem-se em um campo de planejamento que vincula a educação a um projeto político-econômico de desenvolvimento, contudo, agora com um Estado assumindo um papel cada vez mais forte de indutor e condutor das políticas sociais e econômicas, dentro da agenda novo-desenvolvimentista. Assim, o PDE contribuiu para reforçar a perspectiva que associa educação ao desenvolvimento capitalista, "[...] em que a realização de uma educação comprometida com um projeto de sociedade emancipatório e de formação para cidadania é relegado a plano secundário" (FREITAS; SILVA, 2016, p. 85).

É nesse contexto que se situa a nova fase das políticas de ensino superior brasileira liderada pelo PT. Somente a partir da análise do papel desempenhado pela educação no projeto de desenvolvimento em questão é possível compreender as dimensões que balizaram a expansão e reestruturação das instituições de ensino superior públicas e privadas no período Lula e Dilma. Nas gestões do PT, as políticas de ensino superior atuaram no sentido de articulação entre democratização deste nível de ensino e promoção do desenvolvimento econômico do país.

Na esteira desse movimento, temos marcas profundas no campo das Políticas de Ensino Superior brasileiro. Se, nos momentos áureos do neoliberalismo de Fernando Henrique Cardoso (FHC), a base das Políticas Educacionais encontrava-se no discurso acerca da expansão do acesso à educação superior, fundamentalmente de caráter privado, no governo social-liberal de Lula da Silva (2003-2006 e 2007-2010) a questão ganha novos contornos, com uma configuração discursiva em favor da universidade pública e de atendimento de demandas da população historicamente acumuladas. 
No governo Lula da Silva, temos uma nova fase das políticas de ensino superior brasileiras, com a realocação das universidades federais como fonte de investimento e retomada de sua expansão pelo país. Durante seus dois mandatos, foram criadas 14 novas universidades federais e 126 novos campi (BRASIL, 2012), sob defesa da democratização do acesso ao ensino superior e do papel desempenhado pela educação para o desenvolvimento econômico do país.

Essa retomada da educação superior pública brasileira no governo Lula pode ser resumida em três ciclos principais, quais sejam: interiorização, reestruturação universitária e integração regional e internacional. No primeiro ciclo, estendido entre 2003 e 2006, o objetivo principal do governo federal foi a expansão e a interiorização dos campi das Instituições Federais de Ensino Superior (IFESs), mediante o Projeto Expandir, sintetizado no slogan Universidade, expandir até ficar do tamanho do Brasil. No segundo ciclo de expansão, o foco foi de expansão e reestruturação universitária, realizado entre 2007 e 2012, com o Programa de Apoio a Planos de Reestruturação e Expansão das Universidades Federais (REUNI). Concomitantemente ao segundo ciclo, entre 2008 e 2013, iniciou-se o terceiro, propondo-se a promover uma expansão e integração regional e internacional (SILVA, 2014).

Ainda que importante do ponto de vista da defesa da educação pública enquanto direito social, esse avanço nas matrículas da rede federal de ensino superior do governo Lula pode dissimular diversos elementos. Os dados sobre expansão da rede federal de ensino são frequentemente empregados a serviço do governo para comprovar sua vantagem em relação ao período anterior, que se posicionava diretamente contra a educação pública, contudo ocultam os elevados subsídios prestados pelo PT às instituições privadas. Nos termos de Leher (2010), o governo FHC foi fortemente criticado pelo PT por ter ampliado as matrículas do ensino superior privado durante sua gestão, no entanto, as matrículas em instituições privadas subsidiadas pelo Estado foram ainda maiores no governo Lula.

O governo Lula não só manteve o Fundo de Financiamento ao Estudante do Ensino Superior (FIES), como criou o Programa Universidade para Todos (ProUni) em seu mandato, demonstrando o apoio cabal de sua gestão às instituições privadas. Ademais, como postula Cislaghi (2011), foi desconsiderando os déficits de custeio e de pessoal acumulados pelas IFESs do período neoliberal de FHC que o governo Lula definiu a expansão das vagas nas universidades públicas.

A expansão das vagas nas instituições públicas é uma demanda histórica da população brasileira. Valendo-se disso, o governo federal conseguiu grande adesão da sociedade para execução de sua interiorização e expansão. Utilizou-se um caminho ideológico estratégico, que se aproveita da confiança histórica depositava no governo Lula, para transmitir a imagem de que a partir expansão da rede federal de ensino o atendimento das demandas acumuladas da população estaria sendo realizado, renovando a esperança social diante de um histórico de redução no orçamento das universidades públicas e favorecimento do ensino privado (CISLAGUI, 2011). 
Contudo, na medida em que esta interiorização e expansão universitária deram-se em um contexto de grande crise financeira e defasagem profissional das IFESs, o governo do PT poderia estar corroborando a reestruturação destas instituições e a intensificação e precarização do trabalho de seus servidores. Sem garantias efetivas de financiamento adequado, poder-se-ia estar transformando-as em organizações sociais e/ou escolões, prontos para formar os indivíduos polivalentes, flexíveis e empreendedores que o novo modelo de acumulação capitalista demanda.

Nesse contexto, destaca o ANDES-SN (SINDICATO NACIONAL DOS DOCENTES DAS INSTITUIÇÕES DE ENSINO SUPERIOR, 2007), é necessário que os setores atingidos pelos projetos em andamento atentem para o contexto mais geral dessa expansão, situando-a em uma conjuntura nacional e internacional. De igual modo, é necessário desmistificar o conteúdo propagandístico do governo federal, que dificulta a percepção crítica por parte da população. É no contexto de análise deste modelo que se situa nossa pesquisa, propondo-se a desvelar as intencionalidades da interiorização da Universidade Federal de Pernambuco.

A Universidade Federal de Pernambuco é uma instituição consolidada, com 70 anos de existência e com uma cultura acadêmica bem constituída. A instituição conta na atualidade com 110 cursos de graduação, somando um total de 37.116 alunos matriculados. No que se refere à pós-graduação, a instituição oferece 53 cursos de doutorado, 85 cursos de mestrado (sendo 73 acadêmicos e 12 profissionais) e 45 cursos de especialização (dos quais 40 são presenciais e $5 \mathrm{EaD}$ ), totalizando 9.358 discentes matriculados (UNIVERSIDADE FEDERAL DE PERNAMBUCO, 2017). Apesar de sua consolidação, a instituição só realizou o processo de interiorização e expansão de sua estrutura em 2005, mediante o Projeto Expandir, cujo objetivo era "[...] expandir o sistema federal de ensino superior, com vistas a ampliar o acesso à universidade, promover a inclusão social e reduzir as desigualdades regionais" (BRASIL, 2003, p. VI).

Somente após 58 anos de existência e a partir da contemplação de seu projeto de interiorização em 2005, a instituição celebrou convênio com o governo federal para criação de duas novas unidades no interior de Pernambuco. A criação do Centro Acadêmico do Agreste (CAA), mediante a Resolução No 03/2005, e sua implantação do campus no município de Caruaru, a $135 \mathrm{~km}$ de Recife, é fruto desse programa maior de interiorização e expansão universitária do governo Lula. O referido centro resulta do Projeto de Interiorização da Universidade Federal de Pernambuco, concluído com criação do Centro Acadêmico de Vitória (CAV), situado a $51 \mathrm{~km}$ de Recife, no município de Vitória de Santo Antão. O CAA trata-se, deste modo, de um caso exemplar para nosso estudo.

\section{INTENCIONALIDADES DA INTERIORIZAÇÃO DA UNIVERSIDADE FEDERAL DE PERNAMBUCO}

As intencionalidades da interiorização da UFPE podem ser encontradas no documento Projeto de Interiorização da Universidade Federal de Pernambuco (UNIVERSIDADE FEDERAL DE PERNAMBUCO, 2005a). Do ponto de vista do texto institucional, a interiorização da UFPE dá-se em função do compromisso da universidade "[...] com o desenvolvimento da região e, em particular, do estado de Pernambuco, tendo em vista a 
determinação do governo federal de interiorizar a educação superior" (UNIVERSIDADE FEDERAL DE PERNAMBUCO, 2005a, p. 3 grifos da autora). Ou seja, temos a alocação do acesso à educação superior como base para o desenvolvimento econômico regional.

A relação entre educação e desenvolvimento, bem como a sua contribuição para o estado de Pernambuco também ficam evidentes no fragmento a seguir, onde se diz:

\begin{abstract}
Consideramos, portanto, que a criação de uma instituição de ensino superior pública, gratuita e de qualidade, no interior de Pernambuco, na região agreste deste estado, elevará o nível educacional da população, condição imprescindível ao desenvolvimento humano e social. Por outro lado, a necessidade de desenvolvimento de pesquisa para melhoria da qualidade de vida da população torna-se um fator que revela a relevância dessa ação, pois, assim, poderemos fomentar o desenvolvimento econômico da região. Essa é, como sabemos, a plataforma de desenvolvimento regional definida pelo governo do estado que vem se ressentindo da falta de educação superior especializada e gratuita na região e de incentivo à pesquisa (UNIVERSIDADE FEDERAL DE PERNAMBUCO, 2005a, p. 3 grifos da autora).
\end{abstract}

O documento parte da premissa de que a criação de uma instituição de ensino superior pública no interior de Pernambuco permitiria uma maior democratização deste nível de ensino, elevaria o nível educacional da população do Agreste pernambucano e possibilitaria o desenvolvimento econômico local. A democratização do ensino aqui é, assim, ligada à melhoria das condições de vida da população e redução das desigualdades, numa associação entre pobreza e desigualdades de oportunidades.

Essa alocação a educação como fonte de desenvolvimento, embora se dê do ponto de vista da expansão da rede federal de ensino, conforme ressaltado, considera suas contribuições para o desenvolvimento do estado de Pernambuco, representada inicialmente pelo governador Jarbas Vasconcelos (1999-2002 e 2003-2006), mas seguida pela gestão de Eduardo Campos (2007- 2010 e 2011-2014).

É importante ressaltar que, apesar do documento afirmar que a plataforma de desenvolvimento regional estabelecida pelo governo federal é a mesma definida pelo governo do estado, inicialmente não foi possível estabelecer uma confluência direta entre propostas de desenvolvimento em nível federal e estadual. A plataforma de governo do governador Jarbas Vasconcellos funcionava dentro de uma programática neoliberal, trabalhando em consonância com a orientação de Fernando Henrique Cardoso. Ou seja, temos inicialmente uma ausência de confluência direta entre gestão federal e estadual da época.

Não obstante, esta confluência pôde ser empreendida a partir a eleição, em 2007, do governador Eduardo Henrique Accioly Campos, herdeiro familiar e político do exgovernador Miguel Arraes de Alencar, vencido em 1988 e aliado político do então presidente Lula da Silva. Campos foi Ministro da Ciência e Tecnologia de Lula entre 2003 e 2006, quando se habilitou para concorrer ao governo de Pernambuco (MORAIS, 2014). De acordo com Cruz (2018): 
Eleito em outubro de 2006 com a proposta de mudança no estilo de desenvolvimento então prevalecente no Estado, o governo Eduardo Campos, alinhado ideologicamente ao governo federal, adotou como diretrizes centrais para suas ações estratégicas a interiorização do desenvolvimento, com consequente inclusão social, o reequilíbrio econômico e a modernização do sistema de gestão pública. Para tanto, logo após a eleição, já nos primeiros dias de novembro de 2006, foi iniciado um trabalho de avaliação do quadro geral do Estado e da situação da administração pública estadual, que redundou em alterações na estrutura organizacional do Poder Executivo, protagonizando algumas áreas onde o governo, de acordo com essa nova concepção, não poderia estar ausente (Mulher, Recursos Hídricos, Cultura, Esportes, etc.) e garantindo operacionalidade em áreas de atuação cujo desempenho foi considerado inadequado devido à ausência de alinhamento entre a antiga estrutura organizacional do Estado com a do governo federal, principalmente na oferta de serviços públicos e de investimentos estruturadores. Nessa linha, foram criadas novas estruturas (secretarias de Recursos Hídricos, Cidades e Transportes) (CRUZ, 2018, p. 6).

Em consonância com o padrão federal de planejamento, a associação entre desenvolvimento e educação encontrava-se também como um dos eixos estruturantes da gestão de Eduardo Campos em Pernambuco. Exemplos de sua relação entre acesso ao ensino formal e crescimento econômico podem ser encontrados no documento Visão de futuro: Pernambuco 2035, quando se afirma que,

A Educação é componente fundamental do salto para o futuro, elevando o nível de escolaridade, ampliando a taxa de escolarização dos jovens no ensino médio e, principalmente, melhorando a qualidade do ensino. A formação do capital humano aumenta a competitividade, fortalece a civilidade e a democracia, e reduz as desigualdades sociais de forma sustentável (PERNAMBUCO, 2014, p. 46).

O governo do estado, agora em harmonia com a plataforma do governo federal, considera a educação um elemento central para a competitividade e a igualdade de oportunidades. O desenvolvimento, neste ponto de vista, não é compreendido apenas como industrialização, mas como melhoria dos indicadores sociais e acesso à educação. $O$ acesso ao ensino, nesse ponto de vista, fortaleceria a democracia, bem como a civilidade, e possibilitaria a redução das desigualdades (PERNAMBUCO, 2014). Sendo estas aqui, portanto, indicadas como consequências da ausência de oportunidades, não como uma condição sine qua non da sociedade capitalista. Nos termos de Pernambuco (2014), expressos no documento Visão de futuro: Pernambuco 2035:

As empresas de Pernambuco são pouco inovadoras, quando observado o percentual das empresas industriais que inovam (35,3\% em 2011), embora o Estado tenha uma posição destacada no setor terciário, de maior densidade tecnológica, e na capacidade de pesquisa, o que reflete, em grande parte, a ausência de articulação entre universidades e empresas. Para o desenvolvimento de Pernambuco num ambiente de grande disputa competitiva, é necessário que o empresariado assuma uma postura inovadora, e que as instituições de C\&T sejam mais robustas e acessíveis (PERNAMBUCO, 2014, p. 72).

A contribuição da educação para o desenvolvimento econômico era anunciada de forma muito transparente no Projeto de Interiorização da UFPE. Contudo, como podemos vislumbrar no documento acima, ela não se configura como uma dimensão constitutiva 
das políticas educacionais desenvolvidas somente pelo governo federal, mas também acaba por se alinhar com a base das ações da gestão estadual. Em ambos os níveis de governo, temos a alocação da educação, e mais especificamente das universidades, como alicerce das ações governamentais. Sua produção científica e formação de mão de obra são indicadas como fator primordial para o desenvolvimento econômico da região.

Segundo o documento A democratização e expansão da educação superior no país 20032014 (BRASIL, 2015), o desenvolvimento de uma região encontra-se diretamente ligado aos investimentos locais. $O$ incentivo à educação, segundo seu ponto de vista, aumenta a demanda de docentes, técnicos e discentes no local. Ademais, possibilita oportunidades de estudos para os egressos do ensino médio, que muitas vezes abandonam a região em decorrência da ausência de oportunidades locais. Assim, a interiorização da oferta de educação superior, segundo o Ministério da Educação, “[...] é essencial para combater o desequilíbrio no desenvolvimento regional e atingir estudantes sem condições de se deslocar para outras regiões" (BRASIL, 2015, p. 20). Na prática, a criação das novas universidades e campi pautou-se, fundamentalmente, na participação da universidade no desenvolvimento regional.

O “[...] enlace entre educação e desenvolvimento [...]" (BRASIL, 2007, p. 6) é recorrentemente considerado na expansão da educação universitária pelo governo federal. No contexto do PDE, a educação superior baliza-se pelo princípio de desenvolvimento econômico e social, "[...] fazendo da educação superior, seja enquanto formadora de recursos humanos altamente qualificados, seja como peça imprescindível na produção científica-tecnológica, (sic) elemento-chave da integração e da formação da Nação" (BRASIL, 2007, p. 26).

A interiorização da universidade, em sintonia com as determinações do governo federal e estadual, insere-se também no contexto de constituição de uma nova gestão da UFPE, sob coordenação do então Reitor Amaro Lins, eleito para o mandato no período 20032007 e reeleito para a gestão seguinte, 2007-2011. Ou seja, temos também uma conjuntura política interna na universidade em consonância com os projetos antes mencionados. Segundo Lícia Maia (2013), Pró-reitora para Assuntos Acadêmicos (PROACAD) e responsável pela coordenação do processo de interiorização da UFPE na época, tendo por lema a Justiça Distributiva, cujo princípio da equidade norteia os direitos e os deveres do indivíduo, o novo Reitor da UFPE almejava romper com uma hegemonia política que acompanhava esta universidade desde seus primórdios e trazer maior equidade para a instituição.

Ainda segundo Maia (2013), durante o período de gestão de Amaro, várias ações foram desenvolvidas com objetivo de "[...] oportunizar a participação de alunos egressos de classes mais pobres da população à vida da universidade de maneira a firmar o compromisso da UFPE com a sociedade, em particular com os grupos historicamente excluídos do Ensino Superior Público"1 (MAIA, 2013, p. 60). A interiorização da UFPE é apontada pela autora como parte desse compromisso da UFPE com a democratização do

\footnotetext{
'Dentre as ações, podemos citar: implantação do Curso de licenciatura para professores índios; implantação de uma Política de isenção da taxa de inscrição dos vestibulares; Programa de cotas para alunos egressos de escolas do interior do estado e oriundos de escolas públicas e Programas de Bolsas estudantis.
} 
ensino superior para todos os estudantes do estado de Pernambuco, sobretudo para os oriundos dos estratos de renda mais pobres.

Do ponto de vista de Maia (2013), considerando a alta demanda por programas de isenção nas taxas de inscrição nos vestibulares dos alunos dos campi de Caruaru e de Vitória (30\% no Recife e $70 \%$ nas unidades interiorizadas), é possível comprovar a importância para esses jovens da instalação de uma universidade pública na região, dando-lhes possibilidades de fazer uma formação próxima ao local onde vivem e, por outro lado, aumentar as chances do futuro formando se instalar como profissional qualificado na região. Ademais, para a autora, a interiorização cumpre as intenções de elevação dos indicadores sociais no interior do estado e formação de mão de obra especializada para as empresas locais.

No momento de escolha do município de Caruaru como espaço promissor para implantação do campus interiorizado, o Projeto de Interiorização da UFPE (UNIVERSIDADE FEDERAL DE PERNAMBUCO, 2005a) ratifica a necessidade de o Centro Acadêmico fornecer formação de mão de obra especializada para atendimento às demandas dos Arranjos Produtivos Locais (APLs), ou seja, a democratização do acesso à educação é mais uma vez associada à plataforma de desenvolvimento econômico regional. Conforme destaca, para definição da cidade de Caruaru como espaço estratégico para implantação, consideraram-se as seguintes características regionais:

\begin{abstract}
Cadeias e arranjos produtivos predominantes nas áreas da confecção e da agroindústria; Conexões leste/oeste, que vai da Região Metropolitana do Recife ao Sertão Pernambucano, e norte/sul, da Paraíba a Alagoas, e que faz de Caruaru seu principal centro de serviços e negócios e de distribuição de mercadoria; Desigualdade sócio-econômica no desenvolvimento de seu território, apresentando ao norte da região uma realidade econômica e social próspera e ao sul uma grave situação de pobreza, inclusive concentrando 11 dos 13 municípios de menor Índice de Desenvolvimento Humano do Estado (UNIVERSIDADE FEDERAL DE PERNAMBUCO, 2005a, p. 3).
\end{abstract}

Como podemos visualizar acima, os critérios norteadores das áreas de atuação dos cursos do campus Agreste levaram em consideração a demanda regional, tendo como premissa a constituição de um padrão de interiorização que leva em consideração a realidade produtiva local. Assim sendo, considerando as demandas das empresas por formação de mão de obra cada vez mais especializada no capitalismo atual e a crença do governo federal no enlace entre educação e desenvolvimento, buscou-se ofertar cursos em sintonia com a consolidação e fortalecimento dos APLs. Nos termos de Costa (2017):

[...] os processos de expandir e interiorizar, historicamente, tem (sic) transcorrido muito mais pelo interesse em expandir a economia para o interior do país, seus estados e municípios, pelo interesse em formar mão de obra mais qualificada e barata e pela urgência da busca de mais matéria prima para o trabalho, razão para a educação em todos os níveis compor o pacote de medidas determinadas pelo Estado com essa finalidade (COSTA, 2017, p. 255).

Nesse contexto, não resta dúvidas de que a política de expansão e interiorização do ensino superior pública em Pernambuco se configura como uma política de estímulo ao desenvolvimento econômico local. Conforme explicitado, no momento de escolha do

Temporalis, Brasília (DF), ano 18, n. 35, jan./jun. 2018. 
município de Caruaru como espaço promissor para implantação do campus interiorizado, o Projeto de Interiorização da UFPE (UNIVERSIDADE FEDERAL DE PERNAMBUCO, 2005a) ajuizou a necessidade de o Centro Acadêmico fornecer formação de mão de obra especializada e produção de conhecimento científico para atendimento às demandas de seus arranjos produtivos.

Esse caminho fica ainda mais evidente quando se verifica que no processo de alocações das novas unidades de ensino superior, são levadas em conta três dimensões: social, geográfica e de desenvolvimento. No caso das instituições interiorizadas de Pernambuco, percebe-se que todas elas, não somente a de Caruaru, encontram-se em áreas estratégicas e em consonância com os critérios do Ministério da Educação (FIRMINO, 2014).

O processo de interiorização do estado envolveu a construção de seus novos campi nas principais cidades do interior, sendo que duas delas vinculadas a cada uma das três grandes universidades federais já existentes: 1) Universidade Federal Rural de Pernambuco (UFRPE) com a Unidade Acadêmica de Serra Talhada (UAST); b) Universidade Federal de Pernambuco (UFPE) com o Centro Acadêmico do Agreste (CAA) em Caruaru e Centro Acadêmico de Vitória (CAV) em Vitória de Santo Antão; c) Universidade Federal do Vale de São Francisco (UNIVASF) com o Campus Ciências Agrárias e o Campus Petrolina Centro, ambos em Petrolina (FIRMINO, 2014).

Elas visam atender, sobretudo, as demandas por formação de mão de obra especializada e desenvolvimento científico e tecnológico das empresas locais. Isto é, outra vez, nós podemos perceber a alocação da universidade e de seu conhecimento como importante estratégia competitiva para as empresas e para o desenvolvimento regional e nacional.

Esta compreensão e/ou modelo de universidade demonstra claramente a sua inspiração na agenda do Banco Mundial e organismos internacionais. O Banco Mundial (1995) defende, de modo veemente, o papel fundamental desempenhado pelo ensino superior para o desenvolvimento econômico e social dos países subdesenvolvidos. O banco demonstra de diversas formas como os investimentos, neste nível de ensino, contribuem para aumentar a produtividade do trabalho e produzir maior crescimento econômico em longo prazo, elementos que, de acordo com a organização, são fundamentais para o alívio da pobreza².

No prefácio do documento Aprendizagem para todos: estratégia 2020 para a Educação do Grupo Banco Mundial, Atinc (2011) defende que os elevados níveis de desemprego, especialmente entre os mais jovens, podem ser explicados do ponto de vista da incapacidade da educação em formar jovens com as competências corretas para o mercado de trabalho, portanto, a solução para esta problemática estaria na promoção de sistemas de ensino eficientes.

Do ponto de vista do Banco Mundial, a pobreza e o desemprego são considerados não como consequência de condições externas, mas fruto de condições subjetivas do

\footnotetext{
${ }^{2}$ Destacamos aqui que o Banco Mundial defende a expansão e a oferta do ensino superior deve dar-se, sobretudo, mediante setor privado.
} 
trabalhador. Logo, uma vez que são dadas as condições de capacitação para este último, entende-se que os problemas ligados ao desemprego e pobreza estariam solucionados. Ou seja, dentro desta compreensão, para o indivíduo manter-se empregado, basta apenas aproveitar as oportunidades que lhe são dadas.

Nesse contexto, temos em pauta também a ressignificação da teoria do capital humano, onde o acesso ao emprego é posto sob responsabilidade individual. Como destacou Saviani (2013), nas atuais condições de desenvolvimento do capital, mantêm-se a crença na contribuição da educação para o processo econômico-produtivo, marca distintiva da teoria do capital humano, entretanto seu significado é substancialmente alterado.

Segundo o autor, após a crise de 1970, embora a escola tenha mantido seu papel fundamental no processo econômico-produtivo, a teoria do capital humano resignificouse, colocando a responsabilidade pela garantia de empregabilidade no indivíduo. Agora o sujeito quem terá que lutar para adquirir os meios que lhe permitam ser competitivo no mercado de trabalho. A educação passa a ser entendida como um investimento em capital humano individual que habilita as pessoas para a competição pelos empregos disponíveis. O desemprego, portanto, é apontado como resultado das condições subjetivas de cada trabalhador e de sua incapacidade de manter-se empregado. Este parece ser um debate, porém, que desconsidera a lei de acumulação capitalista, apresentada por Marx (2015).

O desemprego, conforme ressalta Marx (2015), é extremamente estratégico para o capital, pois permite um enfraquecimento da capacidade de luta dos trabalhadores, maior competitividade entre eles e suas submissões a condições degradantes de trabalho. 0 capitalismo sempre produz, na proporção de sua extensão, uma população trabalhadora supérflua, que ultrapassa as necessidades médias de sua expansão, tornando-a excedente. Ou seja,

[...] se uma população excedente é produto necessário da acumulação ou do desenvolvimento da riqueza no sistema capitalista, ela se torna, por sua vez, a alavanca da acumulação capitalista e, ao mesmo tempo, condição de existência do modo de produção capitalista. Ela constitui um exército industrial de reserva disponível, que pertence ao capital de maneira tão absoluta como se fosse criado e mantido por ele. Ela proporciona o material humano a serviço das necessidades variáveis de expansão do capital e sempre pronto para ser explorado, independentemente dos limites do verdadeiro incremento da população (MARX, 2015, p. 743).

Portanto, a pobreza e o desemprego não podem ser considerados como aspectos residuais do capitalismo, passíveis de serem solucionados mediante acesso à educação. Eles fazem parte do próprio movimento do capital. "A acumulação de riqueza num polo é, ao mesmo tempo, acumulação de miséria” (MARX, 2015, p. 757). Enquanto perdurar o modo de produção capitalista, perdurará a necessidade de acumulação do capital e do aumento do desemprego e miséria, visto que a lei de acumulação capitalista possui um caráter tendencial. Assim, adverte Marx:

A força de trabalho disponível é ampliada pelas mesmas causas que aumentam a força expansiva do capital. A magnitude relativa do exército industrial de reserva 
cresce, portanto, com as potências da riqueza, mas, quanto maior a relação do exército de reserva em relação ao exército ativo, tanto maior a massa da superpopulação consolidada, cuja miséria está na razão inversa do suplício de seu trabalho. E, ainda, quanto maiores essa camada de lázaros da classe trabalhadora e o exército industrial de reserva, tanto maior, usando-se a terminologia oficial, o pauperismo. Esta é a lei geral, absoluta, da acumulação capitalista (MARX, 2015, p. 756 grifos do autor).

Deste modo, em contrapartida ao que propõe o modelo de desenvolvimento em voga, não é possível pensar a eliminação das desigualdades e desemprego sem considerarmos as mudanças estruturais do ponto de vista societário. Existe um antagonismo entre pleno emprego e lei de acumulação capitalista. Antagonismo este que não pode ser solucionado somente através da democratização da educação, mas mediante a construção de uma nova ordem societária, mais justa e igualitária.

\section{CONCLUSÃO}

O presente estudo buscou desvelar as intencionalidades presentes no processo de interiorização da Universidade Federal de Pernambuco. A partir do levantamento documental e bibliográfico realizado, pudemos verificar que o processo de interiorização da UFPE, em consonância com as determinações do governo federal, visa promover o desenvolvimento regional e nacional.

Entende-se que a criação de uma instituição de ensino superior pública no interior de Pernambuco permitiria uma maior democratização deste nível de ensino, elevaria o nível educacional da população do Agreste pernambucano e possibilitaria o desenvolvimento econômico local. A democratização do ensino é, pois, associada à melhoria das condições de vida da população e redução das desigualdades, numa clara associação entre pobreza e disparidades de oportunidades, em consonância com as determinações dos organismos internacionais e Banco Mundial.

Temos, portanto, no caso das políticas de ensino superior públicas brasileiras, uma confluência com as plataformas do BM, onde a educação é compreendida como um investimento em capital humano individual que habilita as pessoas para a competição pelos empregos disponíveis. Ou seja, onde o desemprego é apontado como resultado das condições subjetivas de cada trabalhador e de sua incapacidade de manter-se empregado, numa forte responsabilização individual pelas condições de pobreza e desigualdade, desconsiderando as condições externas e a lei de acumulação capitalista apresentada por Marx (2015).

\section{REFERÊNCIAS}

ALMEIDA, Jorge; FURTADO, Magda. As reformas, a universidade e a resistência popular. Universidade e Sociedade, Brasília (DF), n. 60, abr. 2017.

ATINC, Tamar Manuelyan. Prefácio. In: BANCO MUNDIAL. Aprendizagem para todos: estratégia 2020 para a Educação do Grupo Banco Mundial: resumo executivo.

Washington (DC), 2011. 
BANCO MUNDIAL. La enseñanza superior: las lecciones derivadas de la experiência. Washington (DC), 1995.

BRASIL. Presidência da República. Decreto n. 6.094, de 24 de abril de 2007. Dispõe sobre a implementação do Plano de Metas Compromisso Todos pela Educação. Disponível em: <http://www.planalto.gov.br/ccivil_03/_at02007-2010/2007/decreto/d6094.htm>. Acesso em: 12 nov. 2017.

BRASIL. Ministério da Educação. A democratização e expansão da educação superior no país 2003-2014. Brasília (DF), 2015.

BRASIL. Ministério da Educação. Análise sobre a Expansão das Universidades Federais 2003 a 2012: relatório da Comissão Constituída pela Portaria $n^{\circ}$ 126/2012. Brasília (DF), 2012.

BRASIL. Ministério da Educação. Expansão das universidades federais: um sonho se torna realidade. Brasília (DF), 2003.

CAMPOS, Claudinei José Gomes. Método de análise de conteúdo: ferramenta para a análise de dados qualitativos no campo da saúde. Rev. bras. enferm., Brasília (DF), v. 57, n. 5, Sept./Oct. 2004.

CASTELO, Rodrigo. O social-liberalismo brasileiro e a miséria ideológica da economia do bem-estar. In: MOTA, Ana Elizabete (Org.). Desenvolvimento e construção de hegemonia: crescimento econômico e reprodução da desigualdade. São Paulo: Cortez, 2012.

CISLAGHI, Juliana Fiuza. A formação profissional dos assistentes sociais em tempos de contrarreformas do ensino superior: o impacto das mais recentes propostas do governo Lula. Serv. Soc. Soc., São Paulo, n. 105, p. 241-266, abr./jun. 2011.

COSTA, Maria Raimunda Santos da. Contextualizando expansão e interiorização no campo da educação brasileira. Revista Exitus, Santarém, v. 7, n. 1, p. 250-276, set./dez. 2017.

CRUZ, Maurício Serra Moreira da. Transformando a gestão pública em Pernambuco: Modelo de Gestão Todos por Pernambuco. Recife, 2018. Disponível em: <http://www.seplag.pe.gov.br/c/publicador_repositorio_documento/get_file?p_I_id=3779 $1 \&$ folderld=38137\&name=DLFE-2423.pdf $>$. Acesso em: 3 fev. 2018.

FIORI, José Luís. O Brasil e seu “entorno estratégico" na primeira década do século XXI. In: SADER, Emir (Org.). Lula e Dilma: 10 anos de governos pós-neoliberais no Brasil. São Paulo: Boitempo, 2013.

FIRMINO, Andresa Lydia da Silva. A interiorização das universidades federais e os arranjos produtivos locais: o caso a Unidade Acadêmica de Garanhuns (UAG/UFRPE). 2014. 119f. Dissertação (Programa de Pós-graduação em Administração e 
Desenvolvimento Rural) - Universidade Federal Rural de Pernambuco, Departamento de Letras e Ciências Humanas, 2014.

FREITAS, Cecília Carolina Simeão de; SILVA, Marcelo Soares Pereira da. O Plano de Desenvolvimento da Educação no contexto do novo desenvolvimentismo brasileiro. RBPAE, v. 32, n. 1, p. 69-88, jan./abr. 2016.

JARDIM, Maria Chaves; SILVA, Márcio Rogério. Programa de aceleração do crescimento (PAC): neodesenvolvimentismo? São Paulo: UNESP, 2015.

LEHER, Roberto. Educação no governo Lula da Silva: a ruptura que não aconteceu. In: MAGALHÃES, João Paulo de Almeida et al. (Org.). Os anos lula: contribuições para um balanço crítico 2003-2010. Rio de Janeiro: Garamond, 2010.

MAIA, Lícia de Souza Leão. Universidade e responsabilidade social: o direito a uma formação de qualidade e gratuita para cada brasileiro. In: LIMA, Iranete Maria da Silva; FRANCO, Maria Joelma do Nascimento; CUNHA, Kátia Silva (Org.). Reflexões e ações sobre Educação, Estado e Diversidade. Recife: UFPE, 2013.

MARX, Karl. O capital: Livro I, V. 2. 29. ed. Rio de Janeiro: Civilização Brasileira, 2015.

MINAYO, Maria Cecília de Souza. O desafio do conhecimento: pesquisa qualitativa em saúde. 14. ed. São Paulo: Hucitec, 2014.

MORAIS, Edima Verônica de. Utilizações das escolas de referência em ensino médio pelo governo do estado de Pernambuco: uma análise do programa de educação integral. Caruaru, 2014. 198f. Dissertação (Mestrado em Educação Contemporânea)-Programa de Pós-Graduação do Centro Acadêmico do Agreste da Universidade Federal de Pernambuco, Caruaru, 2014.

PERNAMBUCO (Estado). Visão de futuro: Pernambuco 2035. Recife, 2014. Disponível em: <http://www.camaraitalianapepb.com.br/imagens/arquivos/pernambuco_2035.pdf >. Acesso em: 10.12.2017.

SAVIANI, Dermeval. História das ideias pedagógicas no Brasil. 4. ed. Campinas: Autores Associados, 2013.

SILVA, Aurélio Ferreira da. O Reuni entre a expansão e a reestruturação: uma abordagem a dimensão acadêmico-curricular. 2014. 183f. Dissertação (Mestrado em Educação)Programa de Pós-graduação em Educação, Faculdade de Educação, Universidade de São Paulo, São Paulo, 2014.

SINDICATO NACIONAL DOS DOCENTES DAS INSTITUIÇÕES DE ENSINO SUPERIOR. AS novas faces da reforma universitária do governo Lula e os impactos do PDE sobre a educação superior. Cadernos ANDES, Brasília (DF), n. 25, p. 1-141, ago. 2007. 
UNIVERSIDADE FEDERAL DE PERNAMBUCO. Anuário estatístico UFPE 2017: base 2016.

Recife, 2017.

UNIVERSIDADE FEDERAL DE PERNAMBUCO. Campus do Agreste. Projeto de interiorização da Universidade Federal de Pernambuco. Recife, maio 2005 a.

UNIVERSIDADE FEDERAL DE PERNAMBUCO. Resolução n 03/2005, de 29 de setembro de 2005. Cria o Centro acadêmico do Agreste e dá outras providências. Recife, set. 2005b. 